Check for updates

Cite this: Chem. Sci., 2019, 10, 10595

๑ All publication charges for this article have been paid for by the Royal Society of Chemistry

Received 20th August 2019

Accepted 3rd October 2019

DOI: $10.1039 / c 9 s c 04153 b$

rsc.li/chemical-science

\section{Twists or turns: stabilising alpha vs. beta turns in tetrapeptides $\uparrow$}

\author{
Huy N. Hoang, (D) a Timothy A. Hill, (D) a Gloria Ruiz-Gómez, ${ }^{\text {ab }}$ Frederik Diness, (D) ac \\ Jody M. Mason, (D) ad Chongyang Wu, (D) a Giovanni Abbenante, ${ }^{a}$ \\ Nicholas E. Shepherd ${ }^{a}$ and David P. Fairlie (D) *a
}

\begin{abstract}
Protein-protein interactions involve hotspots as small as 4 sequential amino acids. Corresponding tetrapeptides have no structure in water. Here we report linking side chains of amino acids $X$ and $Z$ to form 24 cyclic tetrapeptides, cyclo-[XAAZ]- $\mathrm{NH}_{2}$, and stabilise 14-18 membered rings that mimic different kinds of non-regular secondary structures found in protein hotspots. 2D NMR spectra allowed determination of 3D structures for 14 cyclic tetrapeptides in water. Five formed two $(i, i+3)$ hydrogen bonds and a beta/gamma $(6,7)$ or beta $(9,19,20)$ turn; eight formed one $(i, i+4)$ hydrogen bond and twisted into a non-helical $(13,18,21,22,24)$ or helical $(5,17,23)$ alpha turn; one was less structured $(15)$. A beta or gamma turn was favoured for $Z=D a b$, Orn or Glu due to a $\chi 1$ gauche (+) rotamer, while an alpha turn was favoured for $Z=$ Dap (but not $X=$ Dap) due to a gauche (-) rotamer. Surprisingly, an unstructured peptide ARLARLARL could be twisted into a helix when either a helical or non-helical alpha turn $(5,13,17,18,21-24)$ with $Z$ = Dap was attached to the $\mathrm{N}$-terminus. These structural models provide insights into stability for different turns and twists corresponding to non-regular folds in protein hotspots.
\end{abstract}

\section{Introduction}

Protein structure is directed by inherent preferences of amino acids for different folds, ${ }^{1}$ and by packing and solvation effects. Protein-protein recognition is based on interactions between folded secondary structures like $\alpha$-helices, $\beta$-strands, turns and loops. ${ }^{2}$ Thousands of protein-protein interfaces are now known to have bioactive 'hotspots' localised to just 4-8 amino acid segments (1-2 turns), ${ }^{3}$ but $50 \%$ of those sequences have nonregular secondary structures. They include different subtle variations of $\alpha$-, $\beta$ - and $\gamma$-turns (Fig. 1), including non-helical $\alpha$ turns, ${ }^{4,5}$ underscoring the importance of gaining a better understanding of how such turn variations dictate local structure and, ultimately, determine function. New insights to

${ }^{a}$ Australian Research Council Centre of Excellence in Advanced Molecular Imaging, Institute for Molecular Bioscience, The University of Queensland, Brisbane, QLD 4072, Australia. E-mail: d.fairlie@imb.uq.edu.au

${ }^{b}$ Structural Bioinformatics, BIOTEC, Technische Universität Dresden, Tatzberg 47-51, 01307 Dresden, Germany

${ }^{c}$ Center for Evolutionary Chemical Biology, Department of Chemistry, University of Copenhagen, 2100 Copenhagen, Denmark

${ }^{d}$ Department of Biology \& Biochemistry, University of Bath, Claverton Down, Bath, BA2 TAY, UK

$\dagger$ Electronic supplementary information (ESI) available: General experimental methods, materials, chemical synthesis (peptide assembly, cyclisation, cleavage), purification (HPLC), characterisation (CD, NMR), structure calculations, molecular dynamics simulations, and extensive NMR parameters and spectra are available (Tables S1-S22, Fig. S1-S40; 41 pages). See DOI: $10.1039 / \mathrm{c} 9 \mathrm{sc} 04153 \mathrm{~b}$ peptide folding can also enable design of small molecules capable of mimicking different kinds of turn motifs in proteins. Here we investigate tetrapeptides for some new clues to how stereochemical and structural constraints can control folding of the peptide backbone into different turns and helical twists.

Short peptides corresponding to bioactive sequences of proteins rarely show stable structures in water, but when artificially stabilised they can potently modulate protein-protein interactions. A number of strategies have been described for conformationally restricting peptides into beta-turns. One approach is cyclisation, which can promote intramolecular hydrogen bonds that stabilise an $\alpha$-, $\beta$ - or $\gamma$-turn (Fig. 1). ${ }^{6}$ Each of these turn structures is respectively sub-classified by phi and psi angles (Tables S1 and S2, ESI $\dagger$ ) and by $\mathrm{C}_{\alpha}(i)-\mathrm{C}_{\alpha}(i+2), \mathrm{C}_{\alpha}(i)-$ $\mathrm{C}_{\alpha}(i+3)$, or $\mathrm{C}_{\alpha}(i)-\mathrm{C}_{\alpha}(i+4)$ distances between residues.

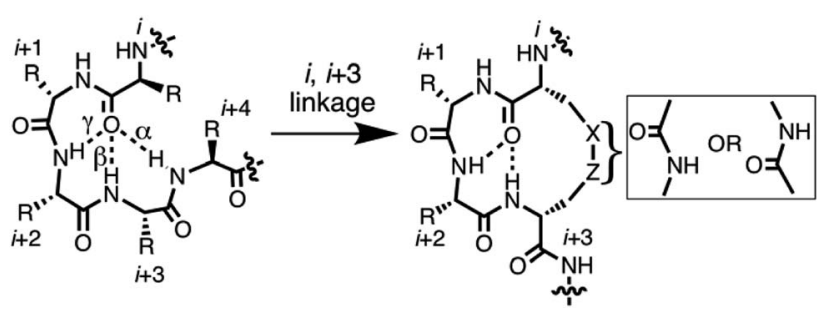

Fig. 1 7-, 10-, 13-membered hydrogen bonded rings define $\gamma^{-}, \beta$ - and $\alpha$-turns respectively (left) that potentially might be stabilised by cyclisation via side chains (right). 
The use of crosslinks between side chains of amino acids in a peptide sequence is a robust and well-established approach to stabilising peptide structure. Cyclisation through linking amine and carboxylate side chains of $\mathrm{L}^{-}$or $\mathrm{D}^{-}$amino acids has been used to enhance peptide bioactivity for many years, ${ }^{7}$ but usually without any clear rationale or understanding of the effect of the length or positioning of the crosslink on three-dimensional structure. The effect of cyclisation on conformation is often inferred through improvements in activity, changes in circular dichroism (CD) spectra, or computer simulations that predict low energy structural ensembles. Incorporating a macrocycle within 10-20 residue peptides often results in local structural changes that are difficult to identify from CD spectra, which only sample the mix of all structures present. Consequently, key requirements for stabilising different turn types in short synthetic peptides are difficult to ascertain from the bulk of literature reports on short peptides. A better understanding about how specific macrocycles can influence structure can enable improved design of bioactive peptides for future mimicry of different folded components of polypeptides.

\section{Results and discussion}

Twenty-four cyclic tetrapeptides (cyclo-1,4)-[XAAZ]- $\mathrm{NH}_{2}$ (1-24) were synthesised, varying in ring size from 14-18 atoms (Table $\mathrm{S} 3, \mathrm{ESI} \dagger)$. In each case $\mathrm{X}$ and $\mathrm{Z}$ have a side chain to side chain linkage between basic (L-Lys, L-Orn, L-Dab, L-Dap) and either an acidic (L-Asp, D-Asp, L-isoAsp, D-isoAsp, L-Glu, D-Glu) amino acid or a diacid (succinic, glutaric), with two intervening Ala residues. They were then systematically examined to discover how side chain-to-side chain cyclisation of residues at the ends of tetrapeptides can affect folding into different turn motifs in water, using circular dichroism (CD) spectra in conjunction with $2 \mathrm{D}{ }^{1} \mathrm{H}$-NMR spectroscopy and molecular dynamics (MD) simulations to characterise peptide structure.

Structural differences were first monitored by CD spectra in water (Fig. 2). Peptides 1-3, 5, 6, 9 and 13 produced two negative molar ellipticity minima between $\lambda \sim 200-220 \mathrm{~nm}$, these wavelengths being expected for helical peptides. ${ }^{\mathbf{8}}$ Peptides 1-3, 6 and 9 also had a positive maximum at $\sim 185 \mathrm{~nm}$. Larger macrocycles ( $>16$ atoms) 4, 8, 11, 12, 15, 16 gave less prominent CD line shapes, while 17-20 containing $\mathrm{X}=\mathrm{D}$-amino acid gave unusual CD spectra. For $\mathrm{X}=$ a carboxylic acid, where the first amide group (Ac-X) has been moved ( 21 and 22) or removed ( 23 and 24), molar ellipticities were more intense and spectral patterns were more similar to that for the structurally wellcharacterised $\alpha$-helix of cyclic pentapeptide Ac-(cyclo-1,5)[KAAAD] $-\mathrm{NH}_{2}$ (25), ${ }^{6 \boldsymbol{d}, \boldsymbol{e}}$ perhaps suggesting some type of helix. ${ }^{5}$ While 21-25 appear to be helical structures, the other compounds are of less certain structural identity but they do serve as useful fingerprints diagnostic of the structure or mix of structures present in water. Overall, there was however a trend where $\alpha$-turn structures (i.e. 5, 17, 18, 21, 22, 23 and 24) gave a more intense molar ellipticity at $\lambda \sim 215 \mathrm{~nm}$ than $\beta$-turn structures (i.e. 6, 7, 9, 15, 19 and 20) (Fig. S1, ESI $\dagger$ ).

CD spectra are based on absorption of left versus right circularly polarized light by amide bonds formed between chiral


Fig. $2 \mathrm{CD}$ spectra of cyclic peptides $(150 \mu \mathrm{M})$ in aqueous phosphate buffer $\left(10 \mathrm{mM}, \mathrm{pH} 7.4,25^{\circ} \mathrm{C}\right)$. (A) 1-4. (B) 5-8. (C) 9-12. (D) 13-16. (E) 17-20. (F) 21-25. Standard 1-letter codes for L-amino acids unless otherwise indicated. Dap $=\mathrm{L}-2,3$-diaminopropionic acid; Dab $=\mathrm{L}-2,4$ diaminobutyric acid; $O=$ L-ornithine; Succ = succinic acid; Glut = glutaric acid; IsoD and Isod are L- and D-aspartic acid respectively, where a side chain carbonyl instead forms the amide bond with the backbone nitrogen atom of the next residue.

amino acids, but tetrapeptides consist only of a few amides. While CD spectral traces are commonly used to interpret threedimensional structure in peptides, they more often lead to incorrect interpretations of peptide structure, ${ }^{9}$ whereas $2 \mathrm{D}$ NMR spectra usually give rise to much more reliable structural characterisations.

To investigate three dimensional structure, we next analysed ${ }^{1} \mathrm{H}$ NMR spectra for 1-24 in 9: $1 \mathrm{H}_{2} \mathrm{O}: \mathrm{D}_{2} \mathrm{O}$, cataloguing their amide coupling constants $\left({ }^{3} J_{\mathrm{NH}-\mathrm{CH} \alpha}\right)$ that inform on residue phi angles (Table S5, ESI $\dagger$ ), and their amide proton temperature coefficients $(\Delta \delta / \Delta T)$ suggestive of hydrogen bonds (Table S6, ESI $\dagger$ ). Fifteen peptides had 1-3 $\beta$-strand-like (>8 Hz) or $\alpha$-helixlike $(<6 \mathrm{~Hz})$ coupling constants $\left({ }^{3} J_{\mathrm{NH}-\mathrm{CH} \alpha}\right)$. Peptides 5-7, 9, 13 and 15 had a C-terminal amide proton with $\Delta \delta / \Delta T<4 \mathrm{ppb} \mathrm{K}^{-1}$, while 6, 7, 9 and 15 had an $i+3$ amide proton with $\Delta \delta / \Delta T<$ $4 \mathrm{ppb} \mathrm{K}^{-1}$, suggesting possible hydrogen bonds. 2D ROESY spectra for peptides 5-7, 9, 13, 15 in water showed 34-46 intramolecular ROEs, that is consistent with well-defined structure (Tables S9-S22, ESI $\dagger$ ). NMR structure calculations indicated that these peptides were turn-like over the three residues AAZ, with peptides 5, 7, 13 giving prominent $\alpha-\mathrm{N}(i, i+$ 2), $\alpha-\mathrm{N}(i, i+3), \beta-\mathrm{N}(i, i+4)$ ROEs. However, each $\mathrm{N}$-terminal 
acetyl moiety projected outwards and was unable to form an intramolecular hydrogen bond for $\mathrm{X}$ to be in a helix.

Inverting the chirality from L-Asp1 (5-7) or L-Glu1 (13) to DAsp1 $(17,19-20)$ or D-Glu1 (18) caused the Ac-NH to reposition closer to the peptide backbone, so that the $\mathrm{CH}_{3} \mathrm{CO}-$ group might form another hydrogen bond. Peptides 17-20 with a $\mathrm{D}^{-}$ residue all had ${ }^{3} J_{\mathrm{NH}-\mathrm{CH} \alpha}$ amide coupling constants $<6 \mathrm{~Hz}$ for Ala2 and Ala3, and a C-terminal amide proton with $\Delta \delta / \Delta T<$ $4 \mathrm{ppb} \mathrm{K}^{-1}$. Peptides 19 and 20 also had $\Delta \delta / \Delta T<4 \mathrm{ppb} \mathrm{K}^{-1}$ for the amide proton of residue 4. 2D ROESY spectra of 17-20 showed 43-71 ROEs and calculated NMR structures (Fig. 3) revealed almost identical structures to their corresponding $\mathrm{L}^{-}$ residue analogues (5-7 and 13) (Fig. 3). The Ac-NH moiety in 1720 was now positioned closer to the helix/turn core, but the acetyl carbonyl oxygen atom was pointing outward. NMR structures suggested no $i \rightarrow i+3$ or $i \rightarrow i+4$ hydrogen bonds. To relocate or remove the Ac-NH moiety, we further synthesised
21-24. Peptides 21-23 had only one ${ }^{3} \mathrm{~J}_{\mathrm{NH}-\mathrm{CH} \alpha}$ amide coupling constant $<6 \mathrm{~Hz}$ (for Ala2), while $\mathbf{2 4}$ had amide coupling constants $<6 \mathrm{~Hz}$ for both Ala2 and Ala3. All these peptides (2124) had two $\Delta \delta / \Delta T<4 \mathrm{ppb} \mathrm{K}^{-1}$ for the amide protons of residue 4 and $\mathrm{C}$-terminal amide. Thus, NMR data indicated an $\alpha$-turn structure $^{4,5}$ for 21-24 in water.

To further characterise structure ensembles for 5-7, 9, 13, 15 and 17-24, average phi and psi angles were compared with

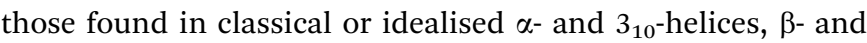
specialised $\alpha$-turns ${ }^{4}$ (where phi, psi $=-58^{\circ},-47^{\circ}$ or $-60^{\circ},-30^{\circ}$

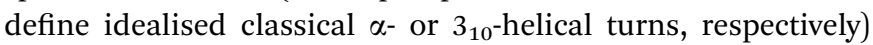
(Tables S1, S2 and S8, ESI $\dagger$ ). NMR-derived structures were superimposed upon these idealised turns and the average backbone RMSDs were calculated to support their structural classifications. In all cases, the first residue $\mathrm{X} 1$ did not correlate with any structure. This fits well with our ability to stereo-invert or relocate or remove the first residue, whilst maintaining
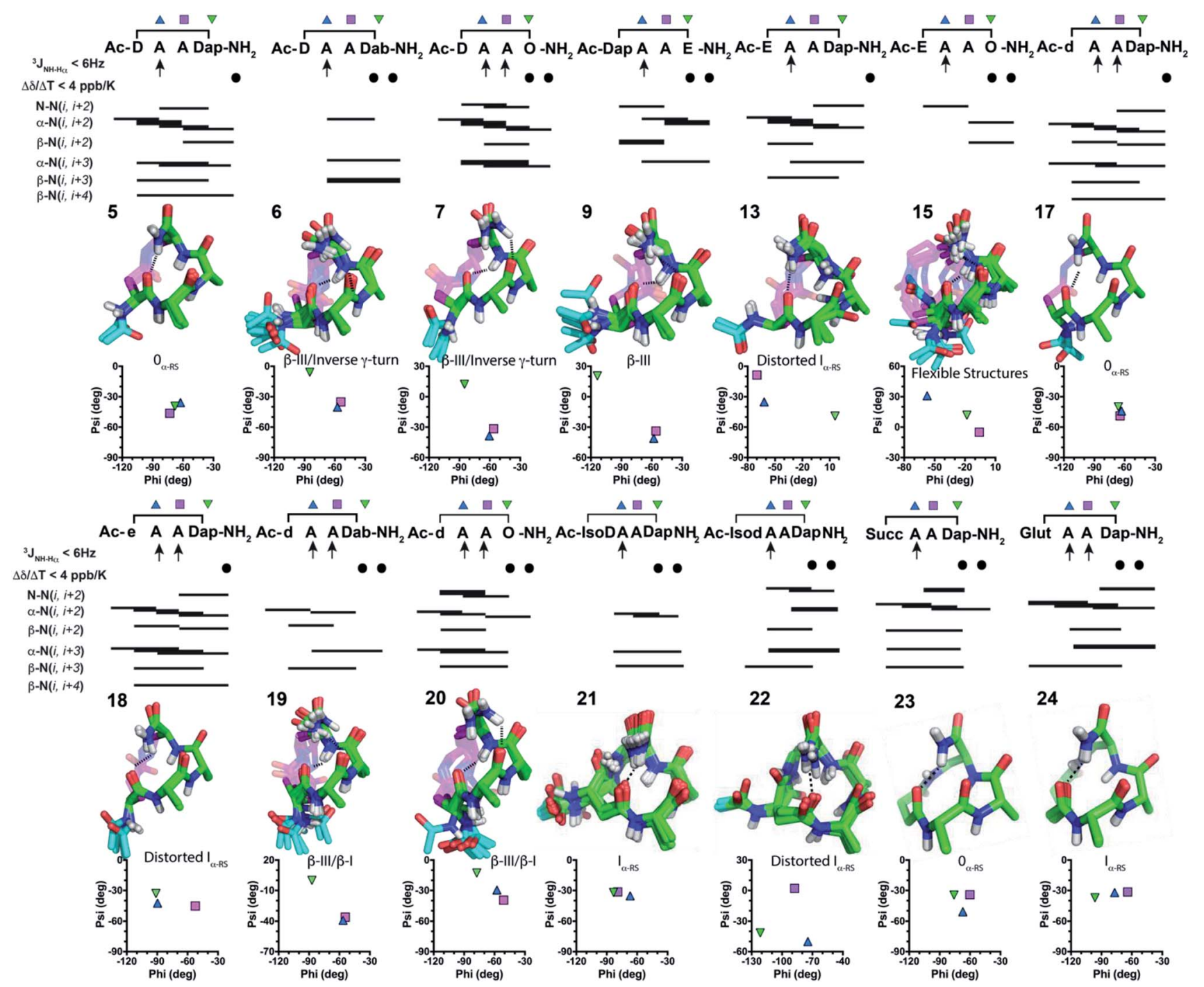

Fig. 3 NMR summaries, 20 lowest energy structures, Ramachandran plots and turn types in water for fourteen cyclic tetrapeptides: 5-7, 9, 13, 15, 17-24 in $\mathrm{H}_{2} \mathrm{O} / \mathrm{D}_{2} \mathrm{O}(9: 1)$ at $298 \mathrm{~K}$. Compounds 5, 13, 17, 18, 21-24 form one hydrogen bond; while 6, 7, 9, 15, 19, 20 form two hydrogen bonds. 
similar overall structures in residues Ala2-Ala3-Z4. Phi and psi angles across these three residues correlated best with an $0_{\alpha \text {-RS }}$ turn for 5, 17 and 23, but with a $\beta$ (III) turn across residues Ala2Ala3 for 6, 7, 9, 19, 20. These angles were variable in residue $\mathbf{Z 4}$, in some cases indicating an inverse $\gamma$-turn $(6,7)$ or $\beta(\mathrm{I})$-turn $(\mathbf{1 9}$, 20). Peptides 13, 18, 21, 22, 24 correlated with an $I_{\alpha-R S}$ turn across Ala2-Ala3. Peptide $\mathbf{1 5}$ only showed $\alpha$-helix or $\beta($ III)-turn character in residue Ala2, all other residues were variable.

Since the cyclisation constraint affects structure stabilisation, we also examined the $\chi 1$ angle for residue Z4 (Fig. 4). The gauche $(-)$ rotamer was adopted for Dap4-containing $5\left(+58^{\circ}\right)$ and $17\left(+59^{\circ}\right)$. This $\chi 1$ angle optimally positions the constraint for $i \rightarrow i+4$ hydrogen bond formation. Peptides $13\left(\chi 1=+50^{\circ}\right)$ and $18\left(\chi 1=+41^{\circ}\right)$ were next closest. For the remaining peptides with a larger side chain in residue $\mathrm{Z} 4$, the $\chi 1$ angle gradually shifted towards the gauche $(+)$ rotamer: e.g. Dab-containing $6(\chi 1$ $\left.=-28^{\circ}\right)$ and $19\left(\chi 1=-23^{\circ}\right)$. For $\beta($ III $)$-like Orn-containing $7(\chi 1$ $\left.=-58^{\circ}\right)$ and $20\left(\chi 1=-59^{\circ}\right)$, this rotamer enabled two $i \rightarrow i+3$ hydrogen bonds to form. MD simulations for 5-7, 9, 13, 15 and 17-20 supported this finding (Fig. 4A).

To summarise Fig. 4, cyclic tetrapeptides with a small side chain at the fourth residue $(\mathrm{Z}=$ Dap) favoured $\chi 1$ in a gauche $(-)$ configuration, which stabilised a psi dihedral angle of $-40^{\circ} \pm 10^{\circ}$ and a C-terminal amide $\mathrm{NH}$ was involved in an $i \rightarrow i+4$ hydrogen bond. By contrast, a larger side chain for $\mathrm{Z}=\mathrm{Dab}$, Orn, Glu favoured a lower energy conformation, $\chi 1$ for gauche $(+)$. NMR structures of peptides where $Z=\operatorname{Dap}(5,13,17,18,21-24)$ had residues Ala2-Ala3-Dap4 and the C-terminal amide folded into $\alpha$ turn structures. Amide carbonyls were aligned to potentially accept hydrogen bonds from amide protons in a peptide appended to the C-terminus of Dap. A distinctive difference between these structures was the intramolecular hydrogen bonding network. One $i \rightarrow i+4$ hydrogen bond was found in peptides 5, 13, 17, 18 and 21-24, whereas two $i \rightarrow i+3$ hydrogen

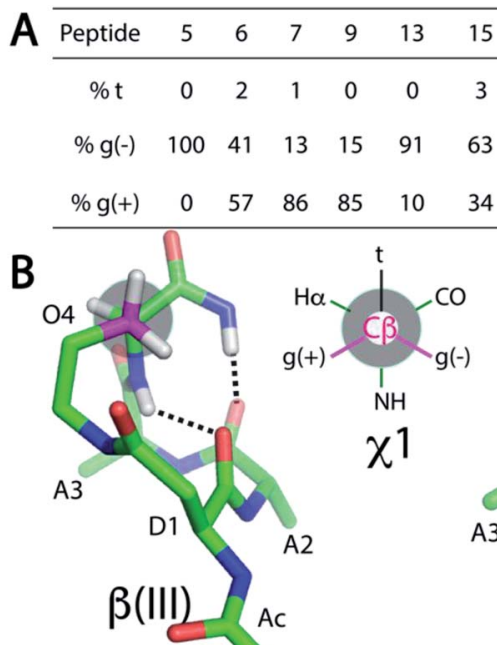

(7)

$\begin{array}{ccccc}5 & 17 & 18 & 19 & 20 \\ 3 & 0 & 0 & 1 & 0 \\ 3 & 99 & 95 & 67 & 0 \\ 4 & 1 & 5 & 32 & 100\end{array}$



(5)
Ac- $\underset{L}{\mathrm{~L}} \mathrm{~A}$ A Dap $-\mathrm{NH}_{2}$

Fig. 4 (A) Rotamer populations for residue Z4 from 50 ns MD simulations of cyclic peptides 5-20. NMR structures of: (B) 7 and 5 show how the $\chi 1$ angle of residue Z4 controls $\beta$ (III)-turn vs. $\alpha$-turn structures.

bonds were present in 6, 7, 9, 15, 19 and 20 (Fig. 3). We therefore considered that $5,13,17,18$ and $21-24$ could be potential $\mathrm{N}$ terminal helix nucleators as their structures support an $i \rightarrow i+$ 4 hydrogen bond that is crucial in an $\alpha$-helical structure.

Next, we searched the PDB for examples of $\alpha$-helix, $\alpha$-turn, $\beta$-III and $\beta$-I turns in hotspots of proteins. We superimposed (PyMOL) our cyclic peptide structures from Fig. 3, calculated by NMR and validated by $\mathrm{MD}$ simulations (Fig. 4A), upon three consecutive residues of the protein secondary structures (Fig. 5). Examples spanned classical $\alpha$-helix $\left(0_{\alpha-\mathrm{RS}}\right), \alpha$-turn $\left(\mathrm{I}_{\alpha-\mathrm{RS}}\right), \beta$-turn type III $\left(3_{10^{-}}\right.$ helix), $\beta$-turn type I and $\gamma$-turn in 12 different protein crystal structures. These different protein turns play important structural roles within human, mammalian and bacterial proteins of very diverse functions. The successful structural mimicry here of these important protein structural motifs by small cyclic peptides

\begin{tabular}{|c|c|c|c|c|c|c|}
\hline & $\begin{array}{l}\text { Compound } \\
\text { (green) }\end{array}$ & $\begin{array}{l}\text { Protein } \\
\text { (yellow) }\end{array}$ & $\begin{array}{l}\text { Turn } \\
\text { type }\end{array}$ & Residues & Description & PDB \\
\hline A & 5 & GLP-1 peptide & 0 - $\alpha \mathrm{RS}$ & $23-27$ & Binds to GLP-1R & 5 vai \\
\hline B & 17 & Bad peptide & 0 - $\alpha \mathrm{RS}$ & $310-314$ & Binds to $B C L-X L$ & $1 \mathrm{~g} 5 \mathrm{j}$ \\
\hline C & 23 & HIV-Rev peptide & 0 - $\alpha \mathrm{RS}$ & $47-51$ & Binds to RNA & 1etf \\
\hline D & 18 & Cholesterol Oxidase & $\mid-\alpha_{\mathrm{RS}}$ & $115-119$ & Contacts FAD & $3 \operatorname{cox}$ \\
\hline$E$ & 21 & $\begin{array}{l}\text { Azotobacter } \\
\text { Ferredoxin }\end{array}$ & $I-\alpha_{R S}$ & $35-39$ & $\begin{array}{l}\text { [Fe-S] binding } \\
\text { site }\end{array}$ & $1 \mathrm{fd} 2$ \\
\hline $\mathbf{F}$ & 24 & T-Cell Surface CD4 & $I-\alpha_{R S}$ & 51-55 & HIV binding site & $3 \mathrm{~cd} 4$ \\
\hline G & 6 & Cone snail neurotoxin & $\beta-111$ & $5-9$ & Kunitz fold & $1 y 62$ \\
\hline H & 7 & Class II MHC & $\beta-I I I$ & $46-49$ & $\begin{array}{l}\text { Adjacent to } \beta \text { - } \\
\text { strand }\end{array}$ & $3 q x a$ \\
\hline$I$ & 9 & $\begin{array}{l}\text { Peptaibol trichovirin } \\
\text { I- } 4 \mathrm{~A}\end{array}$ & $\beta-I I I$ & $5-8$ & Structural roles & $3 s b n$ \\
\hline J & 19 & Human growth factor & $\beta-$-I & $18-21$ & $\begin{array}{l}\mathrm{N}-\mathrm{P}-\mathrm{N}-\mathrm{G} 3: 5 \mathrm{G} 1 \\
\text { bugle turn }\end{array}$ & $3 b 9 u$ \\
\hline $\mathbf{K}$ & 20 & IgE inhibitor & $\beta-1$ & $152-155$ & Beta hairpin & $1 \mathrm{jbf}$ \\
\hline $\mathbf{L}$ & 15 & $\begin{array}{l}\text { Human Pin1 WW } \\
\text { domain }\end{array}$ & $\beta-$-I & $9-12$ & $\begin{array}{l}\text { Ligand Binding } \\
\text { site }\end{array}$ & $1 z \mathrm{cn}$ \\
\hline
\end{tabular}

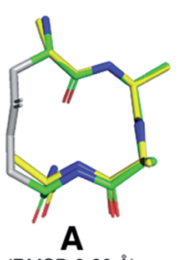

RMSD $0.66 \AA$
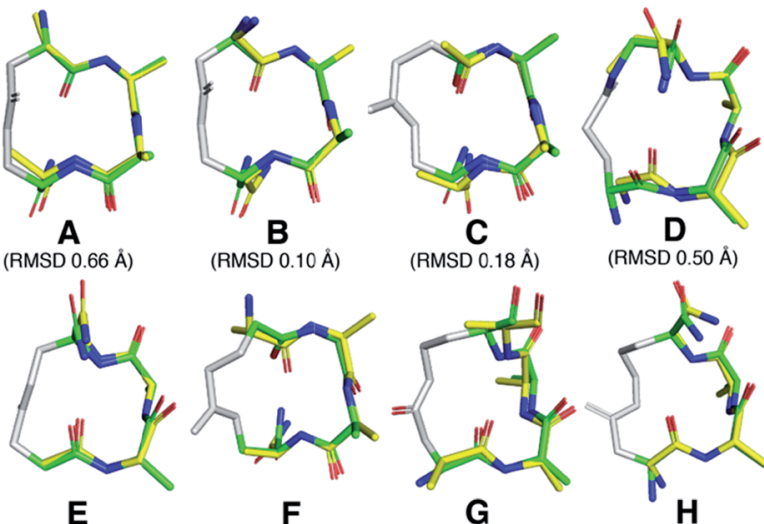

(RMSD $0.80 \AA$ A)

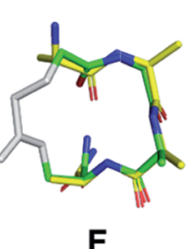

(RMSD $0.24 \AA)$
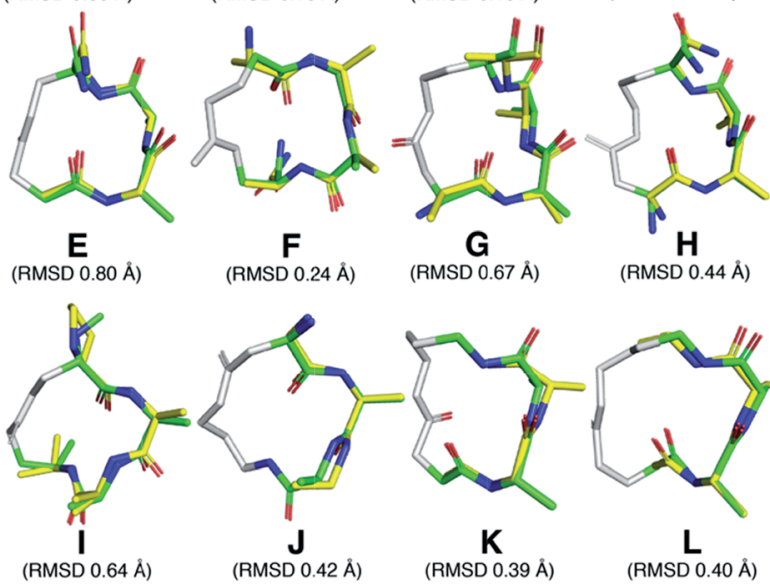

Fig. 5 Average backbone solution structures of $5-7,9,15,17-21$ and 23-24 (green; residues: $A, A, X / Z$ ) superimposed on the three central, consecutive, residues of an $\alpha$-helix, $\alpha$-turn, $\beta$-III turn and $\beta$-I turn from protein crystal structures (yellow). The linkers in these compounds are coloured grey. 
Table 1 Relative helix nucleation in $27-40$ by cycles $5-25^{a}$

\begin{tabular}{|c|c|c|c|c|}
\hline \# & Sequence & Cycle & $f_{\mathrm{H}}$ (buffer) & {$\left[\theta_{222}\right] /\left[\theta_{208}\right]$} \\
\hline 27 & Ac-cyclo-[DAADap]-(ARL) $)_{3}-\mathrm{NH}_{2}$ & 5 & 0.42 & 1.15 \\
\hline 28 & Ac-cyclo-[DAADab]-(ARL) $)_{3}-\mathrm{NH}_{2}$ & 6 & 0.31 & 0.84 \\
\hline 29 & Ac-cyclo-[DAAO]-(ARL) $)_{3}-\mathrm{NH}_{2}$ & 7 & 0.29 & 0.74 \\
\hline 30 & Ac-cyclo-[DapAAE]-(ARL) $)_{3}-\mathrm{NH}_{2}$ & 9 & 0.29 & 0.73 \\
\hline 31 & Ac-cyclo-[EAADap]-(ARL) $)_{3}-\mathrm{NH}_{2}$ & 13 & 0.42 & 0.85 \\
\hline 32 & Ac-cyclo-[EAAO]-(ARL) $)_{3}-\mathrm{NH}_{2}$ & 15 & 0.36 & 0.75 \\
\hline 33 & Ac-cyclo-[dAADap]-(ARL) $)_{3}-\mathrm{NH}_{2}$ & 17 & 0.54 & 0.98 \\
\hline 34 & Ac-cyclo-[eAADap]-(ARL) ${ }_{3}-\mathrm{NH}_{2}$ & 18 & 0.45 & 0.96 \\
\hline 35 & Ac-cyclo-[dAAO]-(ARL) $)_{3}-\mathrm{NH}_{2}$ & 20 & 0.36 & 0.77 \\
\hline 36 & Ac-cyclo-[isoDAADap]-(ARL) ${ }_{3}-\mathrm{NH}_{2}$ & 21 & 0.66 & 1.08 \\
\hline 37 & Ac-cyclo-[isodAADap]-(ARL) ${ }_{3}-\mathrm{NH}_{2}$ & 22 & 0.61 & 0.98 \\
\hline 38 & Cyclo-[SuccAADap]-(ARL) ${ }_{3}-\mathrm{NH}_{2}$ & 23 & 0.65 & 1.03 \\
\hline 39 & Cyclo-[GlutAADap]-(ARL) ${ }_{3}-\mathrm{NH}_{2}$ & 24 & 0.52 & 0.91 \\
\hline 40 & Ac-cyclo-[KAAAD]-(ARL $)_{3}-\mathrm{NH}_{2}$ & 25 & 0.59 & 1.02 \\
\hline
\end{tabular}

provides new capacity to study these structures independent of packing influences in proteins.

Finally, we appended these cyclic tetrapeptides to the $\mathrm{N}$ terminus of nonapeptide ARLARLARL- $\mathrm{NH}_{2}$ (26) to give 27-39. For comparison, we also appended cyclic pentapeptide Ac[KAAAD]- (25) to 26 to give $\mathbf{4 0}$. The relative percent $\alpha$-helicity was measured from $\mathrm{CD}$ spectra using fractional helicities $\left(f_{\mathrm{H}}\right)$ calculated in $10 \mathrm{mM}$ phosphate buffer (Table 1). Each cyclic tetrapeptide had a different $\alpha$-helix nucleating capacity $\left(f_{\mathrm{H}} 0.29-\right.$ $0.66)$ when attached to the N-terminus of the non-helical peptide $26\left(f_{\mathrm{H}}=0.12\right)$. The N-capped 9-residue peptides with the best helix induction (Table 1 ) were 36-38, $40\left(f_{\mathrm{H}} \geq 0.59\right)>33,39\left(f_{\mathrm{H}}\right.$ $\sim 0.53)>27,31,34\left(f_{\mathrm{H}} \sim 0.43\right)$ where an $\alpha$-turn was appended. These data show how subtle differences in cyclic tetrapeptide structure permit or prevent helix nucleation. None of the cyclic tetrapeptides alone has its key carbonyl groups perfectly aligned for helix induction within the cycle itself, yet some are sufficiently aligned to nucleate helicity in attached peptides.

\section{Conclusions}

We synthesised and characterised 24 cyclic tetrapeptides, Ac(cyclo-1,4)-[XAAZ]- $\mathrm{NH}_{2}$, using different $i \rightarrow i+3$ side chain amide crosslinks for cyclization. Such crosslinks have been widely used to improve the bioactivity of peptides, however the cyclic tetrapeptide structures were unknown or inferred on the basis of CD spectral line-shapes, which usually lead to incorrect structure assignments. Here we combined 2D ROESY spectra, amide coupling constants, temperature coefficients and MD simulations to determine their three-dimensional structures in water. Fourteen crosslinked macrocycles were studied with a ring size of 1416 atoms $(\mathbf{5 - 7}, \mathbf{9}, \mathbf{1 3}, \mathbf{1 5}, \mathbf{1 7 - 2 4})$ that gave stable structures in water (Fig. 3). The smaller 14-membered rings tended to be $\alpha$-turns; 5, 17 and 23 were $0_{\alpha-\text { Rs }}$ turns, ${ }^{5}$ while 21 and 22 were $\mathrm{I}_{\alpha-\mathrm{RS}}$ turns ${ }^{4}$ and $\mathbf{1}$ was unstructured. The 15-membered rings adopted $\beta$-turns $(\mathbf{6}, \mathbf{9}$, 19) or $\mathrm{I}_{\alpha-\mathrm{RS}}$ turns ${ }^{4}(13,18,24)$, with 2 being unstructured. The 16membered rings were either $\beta$-III turns $(7,20)$ or did not show stable structures $(\mathbf{3}, \mathbf{1 0}, \mathbf{1 4})$. Larger macrocycles with 17- $(\mathbf{4}, \mathbf{8}, \mathbf{1 1}$,
15) or 18- $(12,16)$ membered rings gave unstable or less stable structures in water (Table S3, ESI $\dagger$ ). All $\alpha$-turn structures $(\mathbf{5}, \mathbf{1 3}, \mathbf{1 7}$, 18, 21-24) had a residue with a small side chain Dap at position $Z$, with its $\chi 1$ angle defining a gauche (-) configuration and favoured one $i \rightarrow i+4$ hydrogen bond. On the other hand, $\beta$-turn structures were observed for peptides $(\mathbf{6}, \mathbf{7}, \mathbf{9}, \mathbf{1 9}, \mathbf{2 0})$ with residues having larger side chains (Dab, Orn, Glu) at this position and favoured two $i \rightarrow i+3$ hydrogen bonds. These results contrast with a previous report that suggested some of these bridges form $\beta$-II and $\gamma$-turns, but those peptides also contained turn-promoting residues (proline, glycine). ${ }^{7 c}$ The Ac-NH moiety in 5-7, 9, 13, 15 did not stabilise the structures. Inverting chirality from L- to D- (17$\mathbf{2 0})$, or repositioning $(\mathbf{2 1}, \mathbf{2 2})$ or removing $(\mathbf{2 3}, \mathbf{2 4})$ the N-terminal Ac-NH moiety, preserved turn structure in the last three residues 2-4 (AAZ).

Each of these model cyclic tetrapeptides were found to successfully mimic corresponding $\alpha$-helix, $\alpha$-turn, $\beta$-III turn and $\beta$-I turn secondary structural components found in biologically important locations in proteins, suggesting the potential for future mimicry of functional properties of such important irregular structures at hotspots in proteins.

We also investigated helix nucleation by these cyclic tetrapeptides at the $\mathrm{N}$-terminus of a non-helical 9-residue peptide sequence ARLARLARL- $\mathrm{NH}_{2}$ (Table 1). Tetrapeptides forming $\beta(\mathrm{III})$-turns $($ e.g. 6, 7, 9, 20), favouring a gauche $(+)$ conformation and two $i \rightarrow i+3$ hydrogen bonds, induced less helicity than $\alpha$ turn forming 5 and 13, which showed a gauche (-) conformation and one $i \rightarrow i+4$ hydrogen bond. Cyclic tetrapeptides with D- rather than L-residues at the (i) position $\mathrm{X}$ were better helix nucleators $(\mathbf{1 7} v s . \mathbf{5}, \mathbf{1 8} v s . \mathbf{1 3})$. Cyclic tetrapeptides Ac-[(isoD or d)AADap] $-\mathrm{NH}_{2}(21 \text { or } 22)^{10}$ and cyclic pentapeptide $25^{6 e}$ have been reported previously. We find that they were better nucleators than 17 and 18. Achiral $\operatorname{diacid}(i) \rightarrow \operatorname{Dap}(i+3)$ crosslinks were also efficient helix nucleators. Succinate at the $i$ position (23) was as good, or better, a helix nucleator than isoaspartate 22 or 25. Interestingly, the glutarate linker (24) was also an effective nucleator (equal to 17), and such dicarboxylate $(i) \rightarrow$ $\operatorname{Dap}(i+3)$ linked tetrapeptides are important new N-terminal helix-nucleating templates easily synthesised, requiring fewer protecting group strategies and cheaper to make than most macrocycles herein.

These new insights into stereochemical and structural influences on peptide folding have led to better definition of peptide turns and helical twists, which mimic the nonregular secondary structures found in bioactive hotspots of proteins, and can inspire design of small molecules to structurally and functionally mimic some of the many subtly different turns and helices in proteins.

\section{Conflicts of interest}

The authors declare no conflicts of interest.

\section{Acknowledgements}

We thank NHMRC (Senior Principal Research Fellowship 1117017) and ARC (DP130100629, DP180103244, CE14010001- 
1) for grants to D. F., Engineering and Physical Sciences Research Council for an Overseas Travel Grant to J. M. (EP/ M001873/2), and Carlsberg Foundation (Denmark) for supporting F. D.

\section{Notes and references}

1 (a) E. G. Hutchinson and J. M. Thornton, Protein Sci., 1994, 3, 2207-2216; (b) C. M. Wilmot and J. M. Thornton, Protein Eng., 1990, 3, 479-493.

2 (a) D. J. Craik, D. P. Fairlie, S. Liras and D. Price, Chem. Biol. Drug Des., 2013, 81, 136-147; (b) L. Nevola and E. Giralt, Chem. Commun., 2015, 51, 3302-3315; (c) J. D. Tyndall, B. Pfeiffer, G. Abbenante and D. P. Fairlie, Chem. Rev., 2005, 105, 793-826.

3 (a) R. S. Harrison, PhD dissertation, University of Queensland, 2011; (b) C. M. Bergey, A. M. Watkins and P. S. Arora, Bioinformatics, 2013, 29, 2806-2807; (c) J. Gavenonis, B. A. Sheneman, T. R. Siegert, M. R. Eshelman and J. A. Kritzer, Nat. Chem. Biol., 2014, 10, 716-722.

4 (a) V. Pavone, G. Gaeta, A. Lombardi, F. Nastri, O. Maglio, C. Isernia and M. Saviano, Biopolymers, 1996, 38, 705-721; (b) D. V. Nataraj, N. Srinivasan, R. Sowdhamini and C. Ramakrishnan, Curr. Sci., 1995, 69, 434-447.

5 H. N. Hoang, R. W. Driver, R. L. Beyer, A. K. Malde, G. T. Le, G. Abbenante, A. E. Mark and D. P. Fairlie, Angew. Chem., Int. Ed., 2011, 50, 11107-11111.

6 (a) T. A. Hill, N. E. Shepherd, F. Diness and D. P. Fairlie, Angew. Chem., Int. Ed., 2014, 53, 13020-13041; Angew. Chem., 2014, 126, 13234-13257; (b) O. Jacobsen, H. Maekawa, N. H. Ge, C. H. Gorbitz, P. Rongved, O. P. Ottersen, M. Amiry-Moghaddam and J. Klaveness, J. Org. Chem., 2011, 76, 1228-1238; (c) Y. W. Kim, P. S. Kutchukian and G. L. Verdine, Org. Lett., 2010, 12, 3046-3049; (d) A. D. de Araujo, H. N. Hoang, W. M. Kok, F. Diness, P. Gupta, T. A. Hill, R. W. Driver, D. A. Price, S. Liras and D. P. Fairlie, Angew. Chem., Int. Ed., 2014, 53, 6965-6969; Angew. Chem., 2014, 126, 7085-7089; (e) N. E. Shepherd, H. N. Hoang, G. Abbenante and D. P. Fairlie, J. Am. Chem. Soc., 2005, 127, 2974-2983; $(f)$ J. W. Taylor, Biopolymers, 2002, 66, 49-75; $(g)$ H. Lin,
Y. Jiang, Q. Zhang, K. Hu and Z. G. Li, Chem. Commun., 2016, 52, 10389-10391.

7 (a) P. W. Schiller, T. M. D. Nguyen and C. Lemieux, Tetrahedron, 1988, 44, 733-743; (b) A. Miranda, S. C. Koerber, J. Gulyas, S. L. Lahrichi, A. G. Craig, A. Corrigan, A. Hagler, C. Rivier, W. Vale and J. Rivier, J. Med. Chem., 1994, 37, 1450-1459; (c) H. R. Marepalli, O. Antohi, J. M. Becker and F. Naider, J. Am. Chem. Soc., 1996, 118, 6531-6539; (d) S. Arttamangkul, J. E. Ishmael, T. F. Murray, D. K. Grandy, G. E. DeLander, B. L. Kieffer and J. V. Aldrich, J. Med. Chem., 1997, 40, 1211-1218; (e) K. A. Carpenter, R. Schmidt, S. Y. Yue, L. Hodzic, C. Pou, K. Payza, C. Godbout, W. Brown and E. Roberts, Biochemistry, 1999, 38, 15295-15304; $(f)$ A. Giolitti, M. Altamura, F. Bellucci, D. Giannotti, S. Meini, R. Patacchini, L. Rotondaro, S. Zappitelli and C. A. Maggi, J. Med. Chem., 2002, 45, 3418-3429; (g) S. De Luca, M. Saviano, R. Della Moglie, G. Digilio, C. Bracco, L. Aloj, L. Tarallo, C. Pedone and G. Morelli, ChemMedChem, 2006, 1, 997-1006; (h) M. Der Torossian Torres, A. F. Silva, F. L. Alves, M. L. Capurro, A. Miranda and V. X. O. Junior, Int. J. Pept. Res. Ther., 2014, 20, 277-287; (i) R. Perlikowska, J. Piekielna, L. Gentilucci, R. De Marco, M. C. Cerlesi, G. Calo, R. Artali, C. Tomboly, A. Kluczyk and A. Janecka, Eur. J. Med. Chem., 2016, 109, 276-286; (j) R. S. Harrison, N. E. Shepherd, H. N. Hoang, G. Ruiz-Gómez, T. A. Hill, R. W. Driver, V. S. Desai, P. R. Young, G. Abbenante and D. P. Fairlie, Proc. Natl. Acad. Sci. U. S. A., 2010, 107, 11686-116891; (k) F. Plisson, T. A. Hill, J. M. Mitchell, H. N. Hoang, A. D. de Araujo, W. Xu, A. Cotterell, D. J. Edmonds, R. V. Stanton, D. R. Derksen, P. M. Loria, D. A. Griffith, D. A. Price, S. Liras and D. P. Fairlie, J. Med. Chem., 2017, 127, 703-714.

8 C. Toniolo, F. Formaggio and R. W. Woody, in Comprehensive Chiroptical Spectroscopy, Wiley \& Sons, Inc., 2012, pp. 499544.

9 R. W. Driver, H. N. Hoang, G. Abbenante and D. P. Fairlie, Org. Lett., 2009, 11, 3092-3095.

10 H. Zhao, Q. S. Liu, H. Geng, Y. Tian, M. Cheng, Y. H. Jiang, M. S. Xie, X. G. Niu, F. Jiang, Y. O. Zhang, Y. Z. Lao, Y. D. Wu, N. H. Xu and Z. G. Li, Angew. Chem., Int. Ed., 2016, 55, 1208812093; Angew. Chem., 2016, 128, 12267-12272. 